\title{
Differentiating data and information
}

\section{John Hodgson}

\author{
European Crop Biotechnology, Vol. 1 \\ and 2 by L.P.M. Lloyd-Evans and \\ Peter Barfoot. BioBridge \\ Publications, Cambridge, UK, 1996, \\ pp.132 and pp.141 \$1112.00, £695.00 \\ (std), \$632.00, £395.00 (not-for-profit), \\ (sfbk); Biotechnology Industry \\ Players. Frost \& Sullivan, London, \\ 1996 , pp. $650, \$ 2144.00, £ 1340.00$ \\ (sfbk or electronic); Biotech on \\ Fingertips. VPM \& Associates, Terre \\ Haute, IN, 1996, pp. 150, (sfbk).
}

Everybody in biotechnology can generate data; few produce information. Consequently, almost everybody in biotechnology has more data than they can handle but still an insufficiency of information. We live and work at a time when, at the click of an electronic switch, we can undertake a tour of the known biological universe and not leave our desks once. Through electronic mail, we can instantly pass on items of potential business or research interest to any number of colleagues sometimes, perhaps, even pausing to embellish the original with a thought of our own. Information processing channels become cluttered, clogged with the detritus of unsought or unintelligible data; a smog of uncoordinated particular matter descends, disorienting us and leaving us bereft of any sense of direction.

In such an environment, there are two solutions. One (the Luddite's) is to staunch the belching supply of data. This is not an option for most biotechnologists. The other solution is to filter it, clarify it, and ultimately, to distill from it pure information. This, in my opinion, is a task that the writers of reports costing hundreds or thousands of dollars should undertake.

Meredith Lloyd-Evans and Peter Barfoot have done just that in their two-volume report on European Crop Biotechnology. Volume 2 is, in essence, a directory of some 400 commercial and academic centers of crop biotechnology in Spain, Italy, Germany, Belgium, France, The Netherlands, Denmark, and the United Kingdom. Each entry gives full contact details for the institutions and the names and specialties of the individual group leaders within each facility. The information is consistently presented and the geographical coverage is even over the countries surveyed.

However, it is volume 1 of European Crop Biotechnology that impresses. The report looks at the market potential of crop biotechnology, and it does so by assessing, not only current and projected future demands, but also the impact of such factors

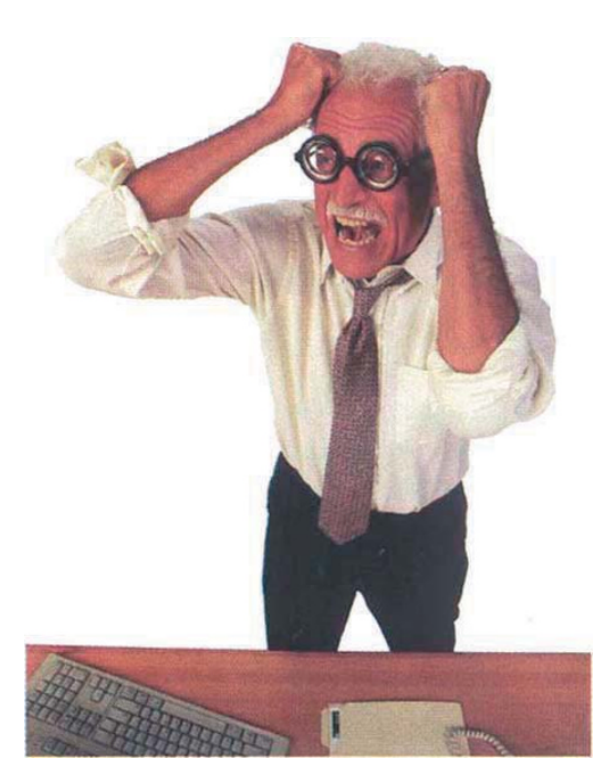

Data overload: Reports that analyze rather than regurgltate biotechnology facts and figures are in short supply.

as $\mathrm{R} \& \mathrm{D}$ strengths, political and regulatory influences, and the structure of the current market. One of the report's conclusions, for instance, is that although wheat and barley occupy the greatest land areas in Europe and have the greatest retail value, investment in research and development on maize or sugar beet or sunflower would potentially be a much more profitable option. The report carefully explains why this should be so, guiding the reader through the intricacies of the seed markets and the geographical suitability of crop varieties, gently but inexorably toward a clear, distilled position. One intriguing section of the report looks at the beneficiaries of plant biotechnology. For both agronomic and quality/composition traits, the report concludes that over the next 15 years or so consumers will continue to benefit the least from plant biotechnology, behind farmers, breeders, and agrochemical concerns. We should not perhaps expect agricultural biotechnology's ride in Europe to get any less bumpy soon.

The Frost and Sullivan report, Biotechnology Industry Players, has, in contrast to European Crop Biotechnology, applied only the crudest of filters. The report profiles uncritically 50 "leading players in the European biotechnology industry." One can certainly quibble with the selection of companies; are Astra, BASF and Bayer really biotechnology players; are Bristol Myers-Squibb and Chiron really European? However, that would be churlish. And it would also diminish the major fault of this 650-page volume: Its almost complete lack of any analytical approach.

Thus, we may learn that BASF was founded in Ludwigshaven in 1895 by Frierich Englehorn, has 106,565 employees, and sold \$31.3 billion worth of product in fiscal 1995. Andto take the next entry in the report-we can find out that Biotrin Holdings was started in 1992 by Cormack Kilty, employs 51 people, and had sales in 1995 of $\$ 2.5$. But what is the meaning of the comparison? The data that are presented provide no basis on which to compare BASF with Biotrin, or the agrochemical combine AgrEvo with the immunology startup, Cantab. That could, I suppose, excuse the absence of analysis. And yet the fact that essentially the same types of data are given for every company does imply that, given time, the busy reader could benefit from cross-referencing between entries. Had the compilers of Biotechnology Industry Players attempted any analysis, the folly of the exercise would have revealed the worthlessness of their data.

Biotech on Fingertips is not strong on analysis either, but it is very strong on filtering. Characterized by its publisher as a biyearly "newsbook" aimed at investors in public companies, Biotech on Fingertips has taken the published information that emanates from public and private biotechnology companies and condensed it considerably. For each company, a single page (or two for more established concerns) summarizes the clinical status and market potential of its products, its quarterly sales (if any), and its collaborations in $\mathrm{R} \& \mathrm{D}$, manufacturing and marketing. This newsbook has another level of selectivity, too: Only 100 or so laterstage companies are cited. Biotech on Fingertips does not lead the reader through the mire, as European Crop Biotechnology does, but it does a pretty reasonable job of making the raw data as undaunting as possible.

\section{Other reports received}

- Gene Therapy R\&D in Canada 96 by M. Brent Charland. Canadian Marketing Group, 1996, pp. 131, (sfbk). Contact Peter Kallai, Tel: 6135679406.

- Directory of Australian Biotechnology Companies. Martin J. Payne, Barbara L. Arnold, Anne Greig (ed.). Australian Biotechnology Association, 1996, pp. 64, (sfbk). Contact Martin Playne, Tel: (03) 95968879.

- The Directory of Biotechnology in France. Alan Faure (ed.). ADEBIO, 1996, pp. 364, (sfbk). Contact Annette Millet, Tel: (33) 45589041 . 